\title{
STAND FOR TESTING SENSITIVITY IMPACT OF RADIO PROXIMITY SENSORS
}

\begin{abstract}
S. Grzywiński ${ }^{*}$, S. Żygadło ${ }^{* *}$
Abstract: The basic parameters of a radio proximity sensor include its sensitivity to single (one-time) impacts with different values. Single impacts are both a desirable parameter used for example to trigger the power source during a projectile shot and very undesirable in sense of safety reason for instance in the case of a fall of a projectile with a sensor on a hard surface. The paper presents a description of the measurement stand and the method of its calibration necessary to correctly execute one-time impacts of specific values during research of radio proximity sensors used in artillery projectiles.
\end{abstract}

Keywords: single impact, Masset hammer, radio proximity sensor

\section{Introduction}

Artillery projectiles are commonly equipped with radio proximity sensors which allow to initiate explosions in a well-defined range above the ground. This increases the destruction effectiveness with utilize fragmentation shells of the ground targets by several times. Such a sensor measures the height of the projectile above the ground and when this parameter corresponds to the required one, it generates a signal of activation. In artillery projectiles, radio proximity sensors utilizing the Doppler effect are commonly used. This type of sensor is characterized by simple construction, small dimensions, high reliability and low unit cost (Żygadło, 2016). One parameter that has a dual role in the operation of the radio proximity sensor's is sensitivity to impact. On the one hand, the impact is a desirable parameter, used to activate the power source or the safety and enforcement mechanism during the firing. At the moment of the shot, the artillery projectile, moving in the barrel of the gun, is subject to very high linear accelerations. According to the applicable shooting tables, it can be estimated that these accelerations for projectile equipped with a radio proximity sensor can achieve $(32500 \div 165000) \mathrm{m} / \mathrm{s}^{2}$. However, according to the applicable defense standards, the used components should enable the construction of a sensor that will be completely proof and resistant to single mechanical impacts (present in the barrel) with a peak acceleration not exceeding $165000 \mathrm{~m} / \mathrm{s}^{2}$. On the other hand, the impact is a very undesirable phenomenon, for example when the projectile with a sensor falls on a hard surface. Due to the safety of use an artillery projectile equipped with a proximity sensor should be resistant to falling from a height of at least $1.5 \mathrm{~m}$ (MON, 1979). In this case, it should never be possible to activate the power supply or other proximity sensor circuits (Grzywiński, 2018). To assess the parameters of the sensor systems, i.e. the correct activation of the power source and the proper operation of the safety and enforcement system, they should be measured in the barrel of the gun during the shot. Such measurements would require very large financial outlays for the necessary equipment, which is why they are practically very difficult to implement. Therefore, alternative methods are used to simulate certain parameters that are close to the parameters in the barrel of the gun during a shot, for example to the abovementioned linear accelerations or impacts.

Stanisław Grzywiński, PhD.: Faculty of Mechatronics \& Aerospace, Military University of Technology, Urbanowicza 2, 00-908 Warsaw, PL, stanislaw.grzywinski@wat.edu.pl

** Stanisław Żygadło, PhD.: Faculty of Mechatronics \& Aerospace, Military University of Technology, Urbanowicza 2, 00-908 Warsaw, PL, stanislaw.grzywinski@ wat.edu.pl 


\section{Description of measuring stand}

The Masset hammer type 70-399 was used to simulate the accretion phenomenon of the linear accelerations to the relevant values occurring in the barrel during the shot. As a result, it was possible to test the sensor's sensitivity to impacts. In order to obtain appropriate intervals of changes in the values of linear accelerations, its calibration was performed. For this purpose, the Brüel \& Kjær instrumentation together with the appropriate software was used. Selected elements of the stand in the form of real-time multi-analysis system allow to ensure quality of performed measurements. The Pulse Reflex application was selected as the measurement software which manage whole stand and provide the tools for recording and analyzing registered signals (Rodzik, 2014). The measuring system consisted of the following elements:

- LAN-XI module - recorder Brüel \& Kjær type 3050-A-060 with accessories (Grzywiński, 16);

- battery module type 2831 with a capacity of $6400 \mathrm{mAh}$, designed to supply the recorder;

- accelerometers type 8339.

To the hammer's arm a sensor type 8339 was attached. It is a low impedance piezoelectric compression accelerometer intended for the measurement of very high-level, continuous vibration and mechanical shock. The sensor is connected to the 3050-A-060 recorder unit. The unit was connected to a laptop with Pulse Reflex software aimed for analyzing vibroacoustic signals. An advantage of the used measuring modules is the built-in TEDS function (Transducer Electronic Data Sweet), which is responsible for the correct programming of the measuring circuits and the input of the transducer parameters. The difference in the values of accelerations was obtained in two ways. Firstly, the hammer's arm was released from latches with increasing numbers, while the next numbers corresponded to increasing the strength of its tension, and thus the force of the impact on the anvil. The second used method to control values of accelerations consisted in applying rubber plugs with precisely selected material parameters. The rubber plugs with dimensions of $\phi 90 \times 100 \mathrm{~mm}$ and increasing hardness were attached to the anvil. Hardness values were selected in accordance with Shore'a scale and respectively were: $40^{\circ} \mathrm{Sh}, 60^{\circ} \mathrm{Sh}, 80^{\circ} \mathrm{Sh}$ and $90^{\circ} \mathrm{Sh}$. The purpose of the mentioned calibration was the assignment of linear acceleration $a_{p}\left[\mathrm{~m} / \mathrm{s}^{2}\right]$ to the number of the latch $(5 \div 25)$ for applied hardness of the plugs. The measurements were carried out at the stand, the diagram of which is shown in Figure 1.
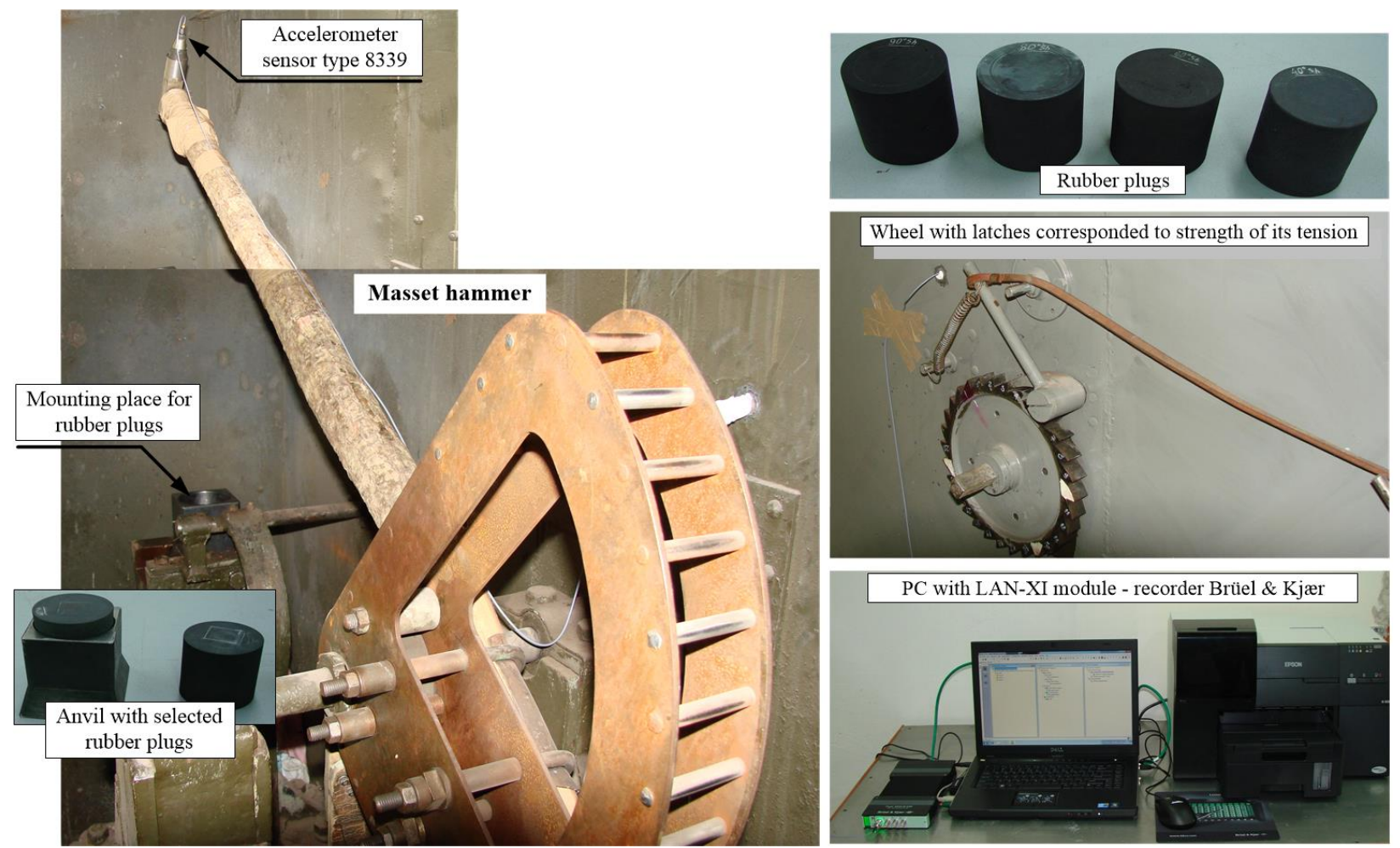

Fig.1. Description of measuring stand

Examples of acceleration waveforms as a function of time for different latches and different values of hardness of rubber plugs are shown in Fig.2. 


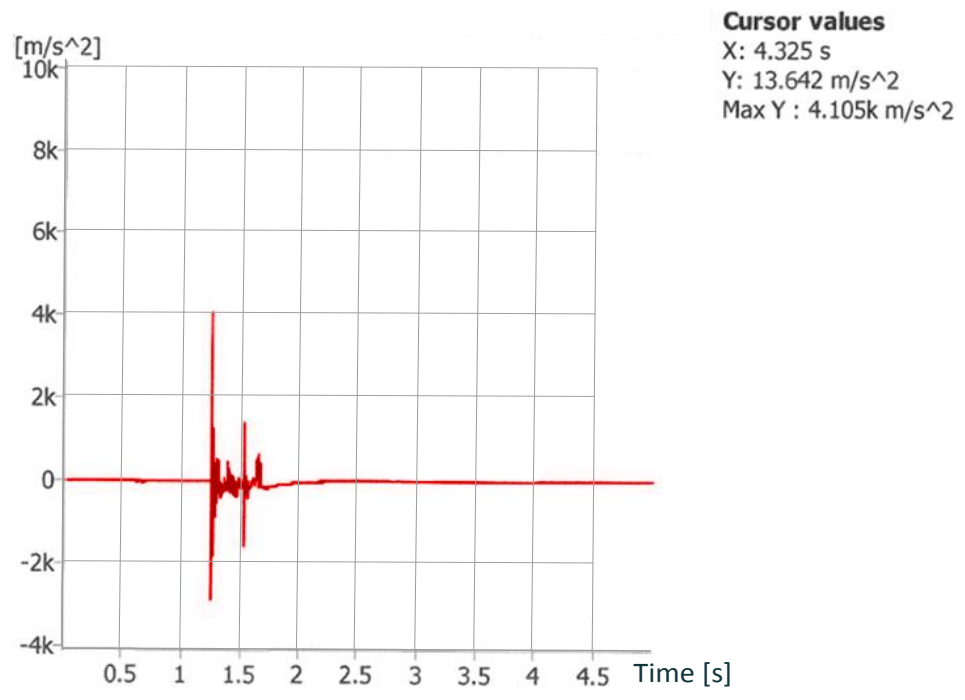

Fig.2a. Examples of acceleration signal in time domain latch 15, hardness $60^{\circ} \mathrm{Sh}$

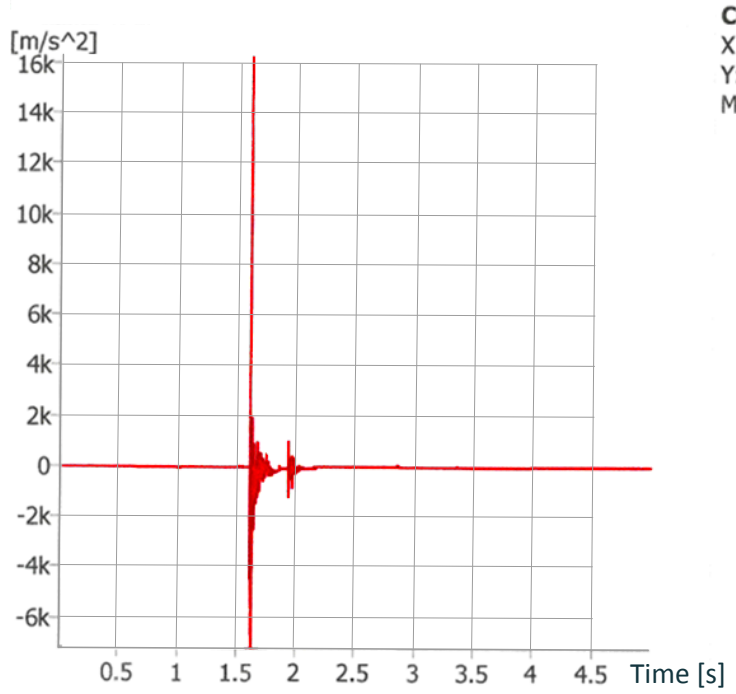

Cursor values

$\mathrm{X}: 4.325 \mathrm{~s}$

$\mathrm{Y}: 14.076 \mathrm{~m} / \mathrm{s}^{\wedge} 2$

$\operatorname{Max} Y: 16.271 \mathrm{k} \mathrm{m} / \mathrm{s}^{\wedge} 2$

Fig.2b. Examples of acceleration signal in time domain latch 20, hardness $90^{\circ} \mathrm{Sh}$

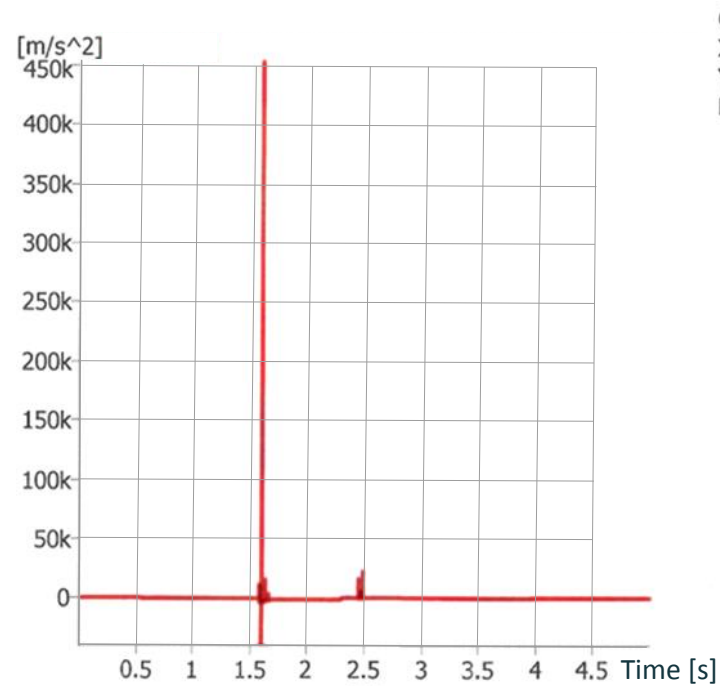

\section{Cursor values}

$\mathrm{X}: 4.325 \mathrm{~s}$

Y: $11.477 \mathrm{~m} / \mathrm{s}^{\wedge} 2$

$\operatorname{Max} Y: 454.133 \mathrm{k} \mathrm{m} / \mathrm{s}^{\wedge} 2$

Fig.2c. Examples of acceleration signal in time domain latch 25, hardness $90^{\circ} \mathrm{Sh}$

The graphs shown in Figure 2 show that: 
- with the increase of the latch number the value of linear acceleration increases with the same hardness of the rubber plug (Fig. $2 \mathrm{~b}$ and c). An analogous situation occurs when increasing the hardness of rubber plug, for the same number of the latch;

- for latch number 25 and the rubber plug hardness of the $90^{\circ} \mathrm{Sh}$ the linear acceleration reaches very high value (Fig. 2c). In this case, the obtained results are subject to increasing errors, which is related to the measurement conditions. The causes of error are vibration of Masset's hammer structure and problems with the strength of mounting the proximity sensor on the hammer's arm.

Graphs of linear accelerations in the function of the latch number for various values of hardness of rubber plugs, are shown in Fig. 3.

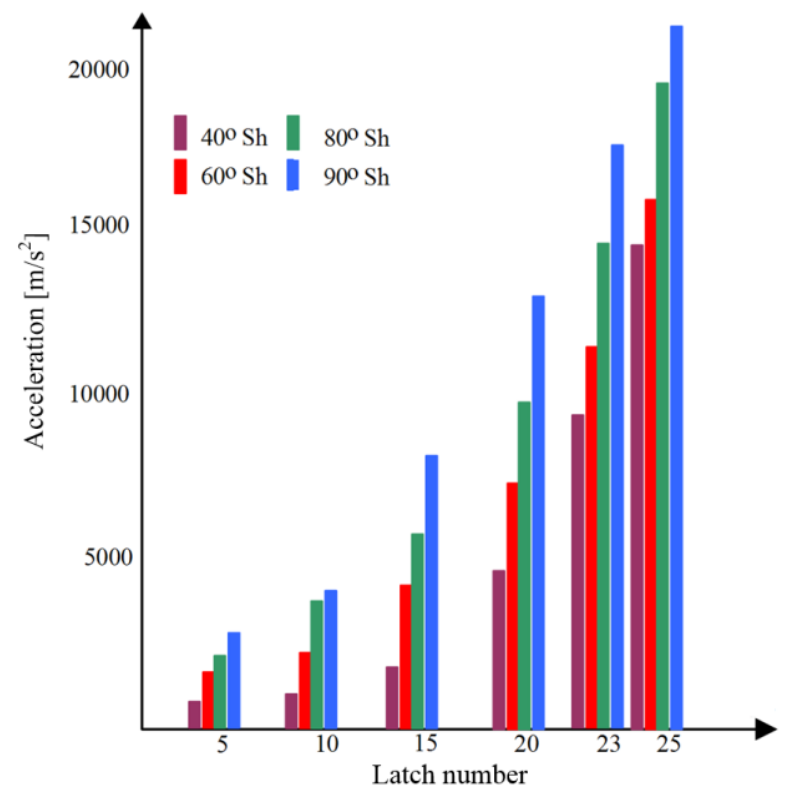

Fig.3. The graphs in the function of the latch number

Based on results it can be concluded that for latch numbers 23 and 25 and high rubber plugs hardness, the results of impacts may be subject to increasing errors caused by design defects of the measuring station.

\section{Conclusions}

The obtained results show that the concept of presented measurement stand and the method of its calibration can be successfully used in testing sensitivity impact of radio proximity sensors. Developed stand can be used to conduct impact tests of radio proximity sensors in a large range of linear acceleration changes. The difference in the values of linear accelerations can be obtained by releasing the hammer arm from each latch numbers and using rubber plugs of different hardness scale. Furthermore, presented stand can be adopted to testing a large number of various devices. Analysis of the results proved the necessity of using calibration process to correctly execute single (one-time) impacts of specific values during research on radio proximity sensors used in artillery projectiles.

\section{References}

MON (2005) Defense standards: NO-06-A101: $2005 \div$ NO-06-A108, Warsaw.

MON (1979) Shooting tables up to $122 \mathrm{~mm} 2$ S1 self-propelled howitzer, Warsaw.

Grzywiński S., Żygadło S., (2018) "Experimental research of the power supply source parameters for sensors in project management". Proceedings of the 24th International Conference - Engineering Mechanics (EM 2018), ISBN 978-80-214-5497-2, Engineering Mechanics, ACAD SCI Czech Republic 2018 , p. 114-117.

Rodzik D., Grzywiński S., Podciechowski M., Żygadło S. (2014) "The use of LAN-XI measurement modules for recording and acquisition of unmanned aircraft vibroacoustic parameters". Mechanic, No. 7/2014, p. 637-644.

Grzywiński S., Żygadło S., (2016) "Design of a remote, multi-channel signal recorder". Mechanic, No. 7/2016.

Żygadło S. (2016) "Proximity fuses for artillery and rocket ammunition", WAT, Warsaw. 